\title{
O USO DAS REDES SOCIAIS COMO FERRAMENTA DE DECISÃO NAS EMPRESAS DE TANGARÁ DA SERRA-MT
}

\author{
Doralice Kochi Santos Silva ${ }^{1}$ \\ Laércio Juarez Melz \\ Airton Montesuma de Carvalho Neto ${ }^{3}$ \\ Ariel Lopes Torres ${ }^{4}$
}

\section{RESUMO}

Um dos setores que mais cresce no mercado mundial é o marketing nas redes sociais, portanto este estudo visou verificar quais os fatores que levam as empresas a utilizarem as redes sociais e qual o nível de sua utilização, e o principal objetivo: como os gestores das empresas de Tangará da Serra têm utilizado as redes sociais em suas decisões, mais especificamente o Facebook que foi constatado nesta pesquisa como o mais utilizado como ferramenta de marketing pelas empresas de Tangará da Serra-MT. Os objetivos foram alcançados através de pesquisa bibliográfica e questionários enviados online, pode-se observar através do resultado dos questionários, que mesmo sendo o assunto do momento, as empresas de Tangará da Serra na sua maioria ainda pouco utilizam dessa ferramenta, ou quando á utilizam não fazem o bom uso da mesma, não realizando a manutenção dá página da empresa.

Palavras-chave: Internet. Informática. Facebook. Marketing. Relacionamento com cliente.

\section{INTRODUÇÃO}

O uso das Redes Sociais tem sido um dos temas mais discutidos. Tem papel muito importante quando se trata de marketing, divulgação pessoal, relacionamento com o cliente. Para Mendes (2012) é esperado aumento do número de pessoas que usam as redes sociais à procura de amigos e de comunidades, de empresas divulgando suas marcas, produtos e serviços. Por isso se nota que as empresas investem nas redes buscando fidelizar seus clientes atuais e trazer novos clientes e mercados para firmar sua marca nesse novo espaço.

Mendes (2012) afirma que o Facebook passou a ser a rede social preferida dos brasileiros com crescimento de $192 \%$ entre dezembro de 2010 e de 2011, batendo o Orkut. Outro dado importante foi constatar que empresas que investem em mídias sociais tem apresentado aumento de receita e melhora nos seus resultados (MENDES, 2012).

1 Acadêmica do curso de Ciências Contábeis da UNEMAT - Campus de Tangará da Serra, e-mail: doralice_kochi@hotmail.com.

${ }^{2}$ Mestre em Engenharia de Produção (UFSCar), Professor do Departamento de Ciências Contábeis da UNEMAT

- Campus de Tangará da Serra, e-mail: laercio@unemat.br.

${ }^{3}$ Contador, Professor do Departamento de Ciências Contábeis da UNEMAT - Campus de Tangará da Serra.

${ }^{4}$ Mestre em Administração (UNEX), Professor do Departamento de Ciências Contábeis da UNEMAT - Campus de Tangará da Serra. 
Segundo Gordon (1999 apud DI AGUSTININI, VILHA, 2002) o uso das redes sociais como ferramenta de marketing de relacionamento é o processo contínuo de identificação e criação de novos valores com clientes individuais e o compartilhamento de seus benefícios durante uma vida toda de parceria. Para Kotler (1999), o uso das redes sociais é marketing que busca o estabelecimento de relacionamentos mutuamente satisfatório de longo prazo com partes-chaves, clientes, fornecedores, distribuidores a fim de ganhar e reter sua preferência e seus negócios no longo prazo.

Vale (2012) afirma que, o marketing nas redes sociais vem ganhando a preferência das empresas por ser uma ferramenta extremamente segmentada. A comunicação feita através das mídias sociais proporciona a possibilidade de aproximação maior com os usuários que têm interesses afins que interagem entre si, compartilhando experiências e opiniões. É nesse ambiente de compartilhamento, que as marcas encontram um verdadeiro paraíso para o marketing nas redes sociais.

Philip Kotler (1999) diz que, com a chegada da internet está se criando verdadeira revolução do marketing, tendo em vista o grande número de compras e vendas pela Internet. Com isso, haverá grande modificação na maneira pela qual as coisas são feitas. Retira-se o dos vendedores e coloca-se sobre os compradores, munidos de quantidades incríveis de informação.

O problema de pesquisa proposto foi: como os gestores das empresas de Tangará da Serra têm utilizado as redes sociais em suas decisões? O enfoque dado foi à rede social Facebook, que vem ganhando mais adeptos no Brasil. Os objetivos específicos foram: a) apresentar o status do uso da internet e redes sociais nas empresas; b) aplicar questionário com empresas usuárias do Facebook para conhecer as formas de utilização; c) analisar o uso do Facebook pelas empresas a partir observação da rede social.

\section{REFERENCIAL TEÓRICO}

O referencial teórico foi estruturado em quatro partes. Na primeira parte apresenta-se o contexto histórico da internet. Na segunda alguns conceitos de redes sociais são apresentados. A terceira parte desenvolve os fundamentos do marketing. A quarta parte apresenta algumas ferramentas que auxiliam a comunicação empresa-cliente. 


\subsection{O desenvolvimento da internet}

Segundo Cavalcanti (1995, p2) “A máquina que veio resolver problemas da agilização da informação foi o computador, construído em 1947, o (ENIAC) Eletronic Integrator and calculator que foi desenhado por um grupo de engenheiros da Pensilvânia nos Estados Unidos (...)" Um achado tão importante quanto o computador, foi à invenção da internet. Internet é abreviação de Inerconnected Network, termo usado para indicar várias redes de computadores interconectados.

Para Magalhães (2005), a maior rede de comunicação do planeta foi criada na década de 1960, pelos Estados Unidos, com propósitos militares, durante a Guerra Fria. O Departamento de defesa norte-americano, por meio da Advanced Research Projects Agency (ARPA- Agencia de Pesquisa e Projetos Avançados), iniciou estudos que culminaram no lançamento da ARPA net. Uma rede nacional de computadores, que permitia o tráfego de dados em todos os sentidos. Assim, promovia-se a comunicação emergencial entre instalações militares e centros tecnológicos e de pesquisa. Esse autor salientou que até meados da década de 1980, a Internet restringia-se a instituições de ensino e pesquisa, em razão do alto custo dos microcomputadores. Em 1981, o sistema ganhou o nome de Internet e, no inicio dos anos 90, criou-se a World Wide Web, a Internet gráfica, com as várias possibilidades hoje conhecidas. Com a diminuição do custo da tecnologia o acesso cresceu. A Internet indica condições favoráveis para definitiva expansão, aumento de qualidade e popularização ainda maior.

No Brasil, a grande expansão tecnológica representada pela internet aconteceu de forma relevante somente em meados de 1991. Ainda que de forma bastante restrita. Foi através da Rede Nacional de Pesquisas, a RNP, que a internet começou a ser utilizada no Brasil. O serviço era inicialmente empregado apenas para interligar universidades aos centros de pesquisa. Sua finalidade era que houvesse maior compartilhamento de ideias. Em 1995 o Ministério de Comunicações e de Ciência e Tecnologia liberou o acesso do serviço para escala comercial. Isso ocorreu através de conexões que eram negociadas com a RNP e a Embratel (ZEVALHOS, 2009).

É notável que as mudanças causadas pela Internet e pela criatividade social advinda desse novo meio facilitam a resposta da retórica à política em mudanças. Mas, as forças de mudança que afetam a cidadania são mais profundas e desnorteantes do que sugeriria a mera observação das transformações tecnológicas. "Para promover os interesses da cidadania, precisamos ficar de olho nas formas cambiantes de vida pelas quais a Pólis continuamente 
fala e se inscreve na vida e pelas quais indivíduos se tornam cidadãos através da fala e da escrita" (BAZERMAN, 2005 apud TARDIN,2010).

A distância de um clique localizam-se empresas, profissionais liberais, provedores de conteúdo, páginas pessoais, serviços, praticamente o mundo todo está ou vai estar na Internet. É como se todos fossem transportados para um único ambiente, com iguais condições de sobrevivência e, por isso, tendo de se adaptar. Estar na Web é uma obrigação. O pensamento corrente é de que em breve só haverá dois tipos de empresa: as que estarão na Web e as que simplesmente não existirão. Utilizar, entender e tirar proveito da Internet é questão de sobrevivência. Assim como a Revolução Industrial acarretou uma série de profundas transformações na organização da produção e também na sociedade, a 'Revolução da Internet' vai provocando uma onda de alterações no curso da história humana (TORRES, 2000).

Antes da Internet, a única forma de uma empresa se relacionar diretamente com seus consumidores eram através da promoção de eventos, serviços de call-center ou malas-diretas. Mesmo assim, era uma comunicação em caráter emergencial, quase sempre com objetivos de resolver algum problema ou comemorar algum fato de importância. A possibilidade de apresentar a empresa, sua filosofia, as pessoas por trás, os compromissos sociais, entre muitas outras informações, foi um ganho típico do advento da Internet (TORRES, 2000).

\subsection{Redes sociais}

Para Castells (1999) rede é um conjunto de nós interconectados. Nó é o ponto no qual uma curva se entrecorta. O mesmo autor também relata que Redes são estruturas abertas capazes de expandir de forma ilimitada, integrando novos nós desde que compartilhem os mesmos códigos de comunicação.

Para Castells (2009) a revolução da tecnologia da informação foi fundamental para a prática de importante reestruturação do sistema capitalista a partir da década de 1980. Nesse processo, o desenvolvimento e as manifestações dessa revolução tecnológica foram moldados pelas lógicas e interesses do capitalismo avançado, sem se limitarem as expressões desses interesses. O sistema alternativo de organização social presente nesse período histórico, o estatismo, também tentou redefinir os meios de consecução de seus objetivos estruturais, embora preservasse a essência desses objetivos, o espírito da reestruturação. 
As novas tecnologias da informação estão integrando o mundo em redes globais de instrumentalidade. A comunicação mediada por computadores gera uma gama enorme de comunidades virtuais (CASTELLS, 1999).

As relações que a empresa mantém com suas principais clientelas podem ser diferencial de concorrência quando seus produtos ou serviços principais. O modo como a empresa distribui informações e sistemas é elemento essencial na força de suas relações. Somente estar conectadas não é mais adequado. As relações empresariais e as comunicações que as sustentam devem existir na trama da rede. O modelo global em rede abre a infraestrutura informática da empresa a todas as principais clientelas, impulsionando a rede para conquistar vantagem perante a concorrência (CASTELLS, 1999).

Segundo Cavalcanti (1995) a possibilidade de acesso imediato e, praticamente, sem nenhuma restrição a informações importantes, das mais variadas áreas do conhecimento humano, em qualquer lugar do mundo, começou gradativamente a moldar parâmetros iguais em regiões muito diversas entre si. Sobre possível resultado do uso da informática nos diferentes lugares.

É o resultado da invasão dos computadores nas empresas e para uso doméstico é que está proporcionando. Cartas, telegramas, mensagens verbais por telefones, podem ser enviados pelo correio eletrônico. Serviços gráficos agora estão à disposição em qualquer lar, através de recursos computacionais. É a introdução de novas formas de aprendizagem e conhecimento através da multimídia permitindo que livros, revistas, enciclopédias sejam usadas eletronicamente em substituição do papel, e com a possibilidade de se ler, ouvir e assistir a um documentário sobre um determinado assunto (CAVALCANTI, 1995 apud TARDIN, 2010). Uma população cada vez mais variada está fazendo uso de seus aplicativos através das redes sociais como Orkut e Facebook. Apesar de consumidas principalmente por adolescentes, essas redes também já utilizadas pelas empresas para fins comerciais (TUBINO, 2010). Rede Social é estrutura social composta por pessoas ou organizações, conectadas por um ou vários tipos de relação. Essas pessoas compartilham valores e objetivos comuns. São, exemplos de redes sociais: Facebook, Orkut, Myspace, Twitter e Linkedln (LAZZAROTTO; MELZ, 2012).

Mídias sociais são o compartilhamento de vídeos, músicas, imagens e textos a fim de que se amplie o conhecimento entre aqueles que promovem a interação (DUBNER, 2011). Segundo Dubner (2011) a tradução do termo Social Media para o português pode ser 
entendido como “[...] uso do meio eletrônico para interação entre pessoas." Diferente das redes sociais para se obter uma mídia social não é necessário que se crie uma conta de usuário/perfil. Segundo Telles (2010) e Altermann (2010), as mídias sociais não surgiram há pouco tempo. Desde o seu principio eram utilizadas para divulgar fatos a toda sociedade ou a um pequeno grupo que interessasse. São exemplos de Mídias Sociais citados por Lazzarotto e Melz (2012): Youtube, Wikipédia, Second Life, Upcoming, Flickr entre outros. A função das redes e mídias pode ser observada no quadro 1.

Quadro 1. Algumas definições e objetivos dos exemplos de Redes e Mídias Sociais.

\begin{tabular}{|c|c|}
\hline Ferramenta & Função \\
\hline Orkut & $\begin{array}{l}\text { Rede Social e site de discussão operado pelo Google, já foi considerada a maior rede social do } \\
\text { Brasil. Perdeu sua colocação para o Facebook. }\end{array}$ \\
\hline Facebook & $\begin{array}{l}\text { Utilidade social possui a função de conectar pessoas, sejam elas amigas ou que trabalham, } \\
\text { estudam e convivem entre si. Ou ainda como diz o slogan do site: "No Facebook você pode se } \\
\text { conectar e compartilhar o que quiser com quem é importante em sua vida". }\end{array}$ \\
\hline Myspace & $\begin{array}{l}\text { Voltado para o entretenimento social, mídia representada pelo perfil de pessoas que } \\
\text { compartilham suas preferências e opiniões sobre música, filmes, televisão entre outros. }\end{array}$ \\
\hline Twitter & $\begin{array}{l}\text { Rede Social similar a um microblog, onde são publicadas mensagens instantâneas de } \\
\text { compartilhamento entre os chamados 'seguidores'. }\end{array}$ \\
\hline Youtube & $\begin{array}{l}\text { Mídia Social, onde é permitido aos seus usuários o compartilhamento de vídeos. Neste tipo de } \\
\text { serviço, é necessário ter uma conta apenas para os usuários que desejam compartilhar seus vídeos } \\
\text { pessoais, caso o contrário o acesso ao conteúdo é livre. }\end{array}$ \\
\hline Wikipédia & Enciclopédia livre e gratuita reúne as mais diversas informações sobre os mais diversos assuntos. \\
\hline Second Life & $\begin{array}{l}\text { Por muitos visto como um jogo, por outros um simulador da vida real ou ainda como exemplo de } \\
\text { mídia social, conforme a tradução do nome já menciona é a 'Segunda Vida' demonstrada em um } \\
\text { ambiente virtual que representa praticamente todas as tarefas desenvolvidas por um ser humano. }\end{array}$ \\
\hline Upcoming & $\begin{array}{l}\text { Site, onde é atribuído aos seus usuários o poder de criar uma agenda ou calendário de eventos } \\
\text { para que possa ser compartilhado com os seus amigos. }\end{array}$ \\
\hline Flickr & Referencial em compartilhamento de imagens. \\
\hline Linkedin & $\begin{array}{l}\text { Comparado a uma rede social, é uma rede de negócios utilizada principalmente por profissionais } \\
\text { que buscam compartilhar conhecimento, informações, novas oportunidades de emprego e } \\
\text { reencontrar antigos colegas. }\end{array}$ \\
\hline
\end{tabular}

Fonte: Wikipédia (2011), Facebook (2011). Lazzarotto e Melz (2012)

Em 2011, encontrava-se mais de 35 milhões de internautas em território nacional. Eles representam aproximadamente $18 \%$ do total da população do país. Esse número em Fevereiro de 2012 saltou para 48,6 milhões de internautas, que representa aproximadamente $25 \%$ do total da população do país. Esses internautas consumiam em média 34 horas mensais em navegação em 2011. Em 2012 a média foi de 44 horas mensais até o mês de Fevereiro. O que 
faz com que o Brasil ocupe a $5^{\text {a }}$ colocação no ranking mundial de conexões à internet (CETIC, 2012).

Há tempos, o Orkut já perdeu apelo mundial: é um ambiente virtual habitado quase exclusivamente por brasileiros. Em dezembro, a rede foi ultrapassada pela primeira vez no Brasil, ao registrar 34,4 milhões de visitantes únicos ante 36,1 milhões da rede criada por Mark Zuckerberg, segundo relatório da empresa de medição com Score (SBARAI, 2012).

Segundo Mendes (2012), o Facebook passou a ser a rede social preferida dos brasileiros. Foi comprovado que essa rede social cresceu $192 \%$ entre dezembro de 2010 e de 2011, batendo o Orkut. Outro dado importante foi constatar que empresas que investem em mídias sociais tem apresentado aumento de receita e melhora nos seus resultados.

\subsection{Marketing e a tecnologia da informação}

Para Las Casas(2001), em Marketing a palavra da moda é mudança. Para ele tando acadêmicos quanto profissionais de diferentes setores tem comentado frequentemente as alterações que acontece no mercado devido as transformações ambientais, mais exatamente nas telecomunicações e na computação. De fato, as novas tendências da comercialização sofreram algumas transformações muito importantes que devem ser consideradas, se as empresas quiserem permanecer no mercado. No entanto, há euforia quanto ao significado da mudança. Muitas pesoas não sabem nem mesmo determinar o que está mudando. São muitas as possibilidades em consideração devido ao acúmulo de informações disponiveis e de avanços tecnológicos desenvolvidos que os profissionais do setor estão visivelmente perdidos diante de tantas transformações.

Marketing de Rede vem a ser a junção do Marketing de Relacionamento e o Marketing Direto. Marketing de relacionamento visa a qualidade do relacionamento com o cliente. Marketing Direto é o relacionamento direto entre o vendedor e cliente. Portanto, o Marketing de Rede possibilita o relacionamento entre ambos. Tal sistema só se consagra com a permanência de relacionamento direto a longo prazo. E este é seu objetivo maior de sucesso (COSTA, 2001).

A informatização elevou a níveis nunca antes imaginados o fluxo e a organização da informação. Pode-se ver, por exemplo, reflexo dessa informatização na íntegra da cadeia de suprimentos, diminuindo os níveis de estoques e aumentando a margem de lucro dos 
varejistas (VAZ, 2011). Na opinião de Las Casas (2001), essas mudanças, estão ligadas a transferências de produtos e serviços e formas de comunicação entre os individuos. Esses aspectos certamente estão afetando todos os setores da administração. Acontece, mais intensamente nas atividades de comercialização. Isso ocorre, em virtude da proximidade dos mercados e da agilidade que pode ser transferida para suas áreas funcionais.

Las Casas (2001) ainda mensiona que segundo Webster (1992), as empresas tiveram que se tornar flexiveis. Já não há condições de operar de forma conservadora. Os desafios ambientais, passaram a existir com maior frequencia e com muita rapidez. Isso exigiu flexibilidade para que pudessem acompanhar as mudanças. Uma empresa poderia iniciar o ano com uma forma de estrutura e terminar com outra. Mesmo as gigantes necessitam ser modernas, abertas a novidades e com a postura de mudar rapidamente, se necessário. Flexibilidade é a chave para o sucesso, mesmo para essas grandes estruturas (LAS CASAS, 2001).

\begin{abstract}
As ferramentas mercadológicas que receberam uma das mairoes influencias das nova tecnologias foram a distribuição e a promoção. A venda virtual, que se utiliza de meios como telefone, televisão e Internet, atingiu números até assustadores.Muitos profissionais de intermediação de produtos e serviços chegaram até mesmo a pensar em perder grande parte de seus mercados por causa do crescimento exagerado desses meios de distribuição. Observou-se uma invasão de comerciantes no marketing direto, obtendo resultados muito positivos. Automóveis também passaram a ser vendidos via Internet. Conforme matéria publicada na Gazeta Mercantil: O comércio eletronico de automóveis começa a ganhar corpo no país. Grandes portais que envolvem centenas de concessionárias de várias marcas e permitem a concretização de negócios estão sendo construídos neste momento(Gazeta Mercantil, 2000).
\end{abstract}

Las Casas (2001) menciona que um dos impactos dessa nova comercialização é a oportunidade que as empresas têm de contatar os clientes de forma individualizada, adaptando suas mensagens diretamente às necessidades de cada um. Para Vaz (2011), um serviço esperado há tempos é que os restaurantes de shopping implementem uma forma de avisar o consumidor por SMS quando o prato dele estivesse pronto. Essa forma, poderia otimizar o tempo comprando algo ou passando no caixa eletrônico para pegar dinheiro. Isso, ao invés de ficar aguardando os dez minutos inúteis esperando a senha do prato aparecer no visor. Com isso o restaurante estaria vendendo um pouco de tempo em vez de só comida. Portanto se você vende atenção (google),se você vende tempo (McDonalds) ou se vende credibilidade (Bancos), com isso voce é uma empresa lucrativa ( VAZ,2011). 


\subsection{Feedback do cliente melhores práticas e benchmarking}

Sordi (2005) diz que o processo de negócio é estruturado a partir de modelos gerenciais e operacionais que abrangem técnicas e métodos de trabalho. Muitos modelos se tornam referência devido aos bons resultados gerados em determinada empresa ou conjunto de empresas. Esses modelos bem sucedidos para determinada atividade são rotulados como melhores práticas. Para um processo de negócios, também pode ser entendido como um processo de negócios com padrão de desempenho classe mundial. $\mathrm{O}$ autor ainda diz que o processo benchmark adota medidas de desempenho relacionadas a melhores práticas, comparando as com processos similares. O objetivo é emular e atingir desempenho similar. Benchmarking pode motivar a inovação e proporcionar foco renovado em áreas que necessitam de aprimoramento e de um alvo de excelência a ser perseguido.

Dois outros conceitos totalmente relacionados á gestão por processos são: produtos e clientes. Eles constituem a própia essencia do processo de negócios, que é gerar algo de valor para aqueles que necessitam e reconhecem a importancia do que está sendo entregue. A esse público denominamos de clientes do processo de negócios. O produto pode ser entendido como o resultado final gerado pelo esforço físico de máquinas ou pessoas, assim como o trabalho lógico desempenhado por um software ou pelo trabalho intelectual de uma pessoa e que na visão do cliente incorpore o conceito de valor agregado. Essa definição ampla de produto abrange não apenas os produtos físicos, mas também os serviço (SORDI,2005).

$\mathrm{O}$ gestor e a equipe que estão diretamente relacionados ao processo de negócios devem estar atentos às necessidades dos clientes. Para isso um canal de comunicação direto para a coleta de Feedbacks. Além de especificar e implementar indicadores de desempenho em níveis de utilização dos recursos, níveis de satisfação dos clientes e outras métricas importantes no relacionamento com os clientes. Segundo a Cliente SA (2011) empresas que estão nas redes sociais obtem mais feedbacks dos clientes. Elas ultilizam das redes sociais como uma eficiente ferramenta para conquistar novos clientes e fidelizar antigos. Facebook, Twiter, como acontece com todos os outros meios de marketing, é preciso conhecer o canal, descobrir como envolver seu público e atualizá-lo constantemente. Na entrevista a Cliente SA (2011) o diretor da área de satisfação do cliente Tim, Paolo Tazzioli, afirma que "a presença nas redes sociais permite que as empresas acompanhem os retornos espontaneos e relevantes dos consumidores, analisando, inclusive, a percepção da qualidade dos serviços prestados". 
Segundo Sordi (2005), o cliente cada vez mais, assume um papel interesssante e ao mesmo tempo complexo com relação aos processos de negócios. Nao só consomem seus produtos e serviços, mas estão cada vez mais inter-relacionados e participativos. Por exemplo, atuando diretamente na definição e especificação final dos produtos e serviços gerados pelo processo. Assim, eles passam a ser considerados não apenas consumidores, mas também parte da própria operação do processo de negócios.

\section{METODOLOGIA}

Esta pesquisa teve como classificação exploratória que segundo Richardson (1999), este tipo de pesquisa proporciona maior informação sobre determinado assunto, facilita a delimitação do tema de um trabalho, define objetivos ou formula as hipóteses de uma pesquisa. E uma caracteristica interessante da pesquisa exploratória segundo Beuren (2004) consiste no aprofundamento de conceitos preliminares sobre determinada temática não contemplada de modo satisfatório anteriormente. Sendo assim foi realizado procurando obter informações de como o cenário virtual promove o marketing de rede podendo ou não interferir no sucesso e oportunidade de negócio das empresas de Tangará da Serra.

O site da wikipédia foi utilizado como fonte bibliográfica por conter informações atuais sobre o tema escolhido, e por se tratar de um tema novo, alguns questionamentos não são encontrados em livros bibliográficos.

Segundo Vieira (2008) a wikipédia torna mais aguda a idéia de uma inteligência coletiva na medida em que permite que não apenas especialistas escrevam uma enciclopédia, mas pessoas comuns também adicionem verbetes e estes passem pelos crivos coletivos. O trabalho, portanto, é colaborativo. Um sujeito qualquer propõe um verbete, que será revisado por outros tantos, lido por outros mais, acrescido de novas informações, novamente lido e alterado. O coletivo decide pela consistência e pertinência das informações. O coletivo produz conteúdo a partir de colaborações individuais.

Com relação aos procedimentos classifica-se como levantamento, survey (MARTINS; FERREIRA, 2011). O método foi utilizado para atender ao objetivo de aplicar questionário com empresas usuárias do Facebook para conhecer as formas de utilização, também foi utilizada bibliográfica a partir de estudos já realizados.

A abordagem do problema foi qualitativa que segundo Neves (1996) a pesquisa qualitativa faz emergir aspectos subjetivos, ou mesmo conscientes, de maneira espontanea. 
São usadas quando se busca percepções e entendimento sobre a natureza geral de uma questão, abrindo espaço para a interpretação, na sua marioria são feitos no local de origem dos dados. A falta de exploração de um certo tema na literatura disponível, o caráter descritivo da pesquisa que se pretende empreender ou a intenção de compreender um fenômeno complexo na sua totalidade são elementos que tornam propício o emprego de métodos qualitativos .

O espaço de análise foi delimitado com relação ao local, o período e o universo de estudo. O local selecionado é Tangará da Serra-MT. O período da pesquisa foi fevereiro a setembro de 2012. O universo de estudo foi consituído por as empresas de Tangará da Serra que utilizam a rede social Facebook. Limitou-se à essa rede social, pois, é a rede que tem crescido mais no Brasil em número de usuários. Segundo Xavier (2011):

\begin{abstract}
Em uma ação investigativa, elaborar um método e segui-lo é fundamental para obter sucesso na empreitada academica. A adoção de um método consciente representa a lucidez do pesquisador em realizar movimentos estratégicos, organizados e planejados em realizar movimentos estratégicos, organizados e planejados com antecedencia para executar um fazer com produtividade e transparencia máximas.
\end{abstract}

A pesquisa foi realizada com uso da Internet dentro do site de relacionamento Facebook. A busca por empresas foi em tempo real buscando contato com as empresas da cidade. O método foi a busca por palavras-chaves: Empresas em Tangará da Serra. Após encontradas as empreas foram adicionadas aos contatos dos pesquisadores para contato pessoal. Após os estudos bibliográficos foi realizada pesquisa de campo. Nesta fase foi enviado um link com o questionário online para as empresas adicionadas aos contatos para que os objetivos fossem alcançados. Esta pesquisa foi realizada do dia 30/08/2012 à 15/09/2012, enviando-se o questionário para 127 empresas de vários ramos em Tangará da Serra-MT. Somente 21 empresas responderam, após vários contatos, correspondendo ao um total de $16,54 \%$ do público alvo analisado. Esta pesquisa foi respondida por gerentes, proprietários, diretores, vendedores e orientadores das empresas. Devido o baixo índice de empresas que responderam o questionário, houve a necessidade de buscar meios alternativos. Optou-se por fazer observação simples para analisar todas as empresas que receberam o link com o questionário. Alguns dados quantitativos foram levantados visando conhecer o uso da rede social pelas empresas localizadas. Os dados foram tabulados e depois analisados para entender o perfil das empresas que utilizam o Facebook em Tangará da Serra. 


\section{RESULTADOS}

\subsection{Características da amostra}

Nesta seção apresentam-se as características dos entrevistados, os tipos de equipamento utilizados, os diversos ramos que utilizam o Facebook. Através da coleta e análise dos questionários pode-se obter um resultado de 21 entrevistados. Deste 10 mulheres e 11 homens havendo ai um equilíbrio entre homens e mulheres, constatando que há igualdade, conforme segue na tabela 01 . A faixa etária de menos de 18 anos obteve um resultado de $5 \%$, 18 á 21 anos 4\%, 22 á 24 anos 29\%, 24 á 35 anos 38\% e acima de 35 anos 29\%, neste caso foi constatado que há um empate em número de entrevistados de 22 á 24 anos e acima de 35 anos e os entrevistados de 24 á 35 anos são quem mais gerenciam esse meio de comunicação com $38 \%$.

Tabela 01. Idade versus Sexo dos entrevistados, Tangará da Serra, 2012, em número de respostas.

\begin{tabular}{cccc}
\hline Idade & Feminino & Masculino & Total \\
\hline Acima de 35 anos & 3 & 3 & 6 \\
De 24 a 35 anos & 4 & 4 & 8 \\
De 18 a 21 anos & 0 & 1 & 1 \\
De 22 a 24 anos & 3 & 3 & 6 \\
Não desejo responder & 0 & 0 & 0 \\
\hline TOTAL & $\mathbf{1 0}$ & $\mathbf{1 1}$ & $\mathbf{2 1}$ \\
\hline
\end{tabular}

Em relação às expectativas esperadas pelo uso do Facebook os benefícios que este trouxe foram, na sua maioria, divulgação da marca $(61,92 \%)$. As demais opções apresentaram a mesma frequência de resposta, conforme segue a Tabela 02. Percebe-se que, nas empresas que responderam o questionário, o potencial do uso das redes sociais não tem sido bem explorado. Opções que poderiam agregar valor, como agilidade em métodos e processos de atendimento, são pouco percebidas. Também a identificação de novas oportunidades não é percebida pelas empresas (Tabela 02).

Tabela 02. Respostas à questão: com a utilização das redes sociais como ferramenta, quais os benefícios que estas trouxeram para empresa? Tangará da Serra, 2012, em número de respostas.

\begin{tabular}{ccc}
\hline & $\mathbf{\%}$ & Quantidade \\
\hline Divulgação da marca e produtos & 61,92 & 13 \\
Conhecer o perfil do cliente & 9,52 & 2 \\
Agilidade em métodos e processos de atendimento & 9,52 & 2 \\
Aumento de vendas dos produtos ofertado & 9,52 & 2 \\
\hline
\end{tabular}


O uso das redes sociais como ferramenta de decisão nas empresas de Tangará da Serra-MT

Doralice Kochi Santos Silva, Laércio Juarez Melz, Airton Montesuma de Carvalho Neto, Ariel Lopes Torres

\begin{tabular}{ccc} 
Novas oportunidades de negócio & 9,52 & 2 \\
\hline Total geral & $\mathbf{1 0 0 , 0 0}$ & $\mathbf{2 1}$ \\
\hline
\end{tabular}

O tipo de conexão utilizada que mais se destacou foi à via telefônica (tecnologia DSL) com $85,72 \%$ dos entrevistados, seguidos por modem via rádio $(9,52 \%)$ e modem via cabo $(4,76)$, conforme Tabela 03. Ressalte-se que novos meios de comunicação tem aumentado sua participação, notadamente, o uso de celulares e tablets conectados à internet. Empresas atentas às novas tecnologias poderiam ter profissionais conectados às $100 \%$ do tempo por meio desses aparelhos.

Tabela 03. Tipo de internet que a empresa utiliza, Tangará da Serra, 2012, em número de respostas e percentual.

\begin{tabular}{ccc}
\hline & \% & Quantidade \\
\hline Modem digital via telefônica (tecnologia DSL) & 85,72 & 18 \\
Modem via rádio & 9,52 & 2 \\
Modem via cabo & 4,76 & 1 \\
\hline TOTAL GERAL & $\mathbf{1 0 0 , 0 0}$ & $\mathbf{2 1}$ \\
\hline
\end{tabular}

Em relação aos equipamentos utilizados para acessos as redes sociais e como também uma ferramenta de trabalho constata-se que a maioria dos entrevistados $(57,14 \%)$ afirmaram que possuem computador de mesa, outros 33,34 \% dos empresários/responsáveis apontaram que usam uma ferramenta de fácil mobilidade que é o notebook, e também netbook e telefone celular móvel foram apontados por 4,76\% cada como um equipamento utilizado para esses acessos, conforme a tabela 04. Esse resultado confirma o maior uso da internet via linha telefônica apresentado na tabela 03. Confirma também o baixo uso de tecnologias como o celular no processo.

Tabela 04. Equipamento utilizado para esses acessos, Tangará da Serra, 2012, em número de respostas e percentual.

\begin{tabular}{|c|c|c|}
\hline & $\%$ & Quantidade \\
\hline Computador de mesa & 57,14 & 12 \\
\hline Notebook (Computador Portátil) & 33,34 & 7 \\
\hline Netbook (Computador Super portátil) & 4,76 & 1 \\
\hline Telefone celular móvel & 4,76 & 1 \\
\hline Total geral & 100,00 & 21 \\
\hline
\end{tabular}


$\mathrm{Na}$ tabela 05, constatou-se que o tempo de dedicação pelos usuários em porcentagem se mostra: menos de 30 minutos 19\%, 30 minutos a 2 horas 29\%, 2 á 3 horas 24\%, 4 ou mais horas $29 \%$.

Tabela 05. Tempo dedicado ao site do Facebook, Tangará da Serra, 2012, em número de respostas e percentual.

\begin{tabular}{cc}
\hline Tempo & \% \\
\hline Menos de 30 minutos & $19 \%$ \\
30 minutos a 2 horas & $29 \%$ \\
2 a 3 horas & $23 \%$ \\
4 ou mais horas & $29 \%$ \\
\hline TOTAL & $\mathbf{1 0 0 \%}$ \\
\hline
\end{tabular}

A área responsável por gerir a participação da empresa nas redes sociais na sua maioria foi identificada como a diretoria e seguida da área de vendas. Pode-se notar que essa gestão é feita geralmente pelo proprietário ou sócio proprietário da empresa. Em sua minoria há funcionários contratados especificamente para gerenciar á página da rede social da empresa (figura 01).

Figura 01. Responsável pelas redes sociais dos entrevistados, Tangará da Serra, 2012, em percentual de respostas.

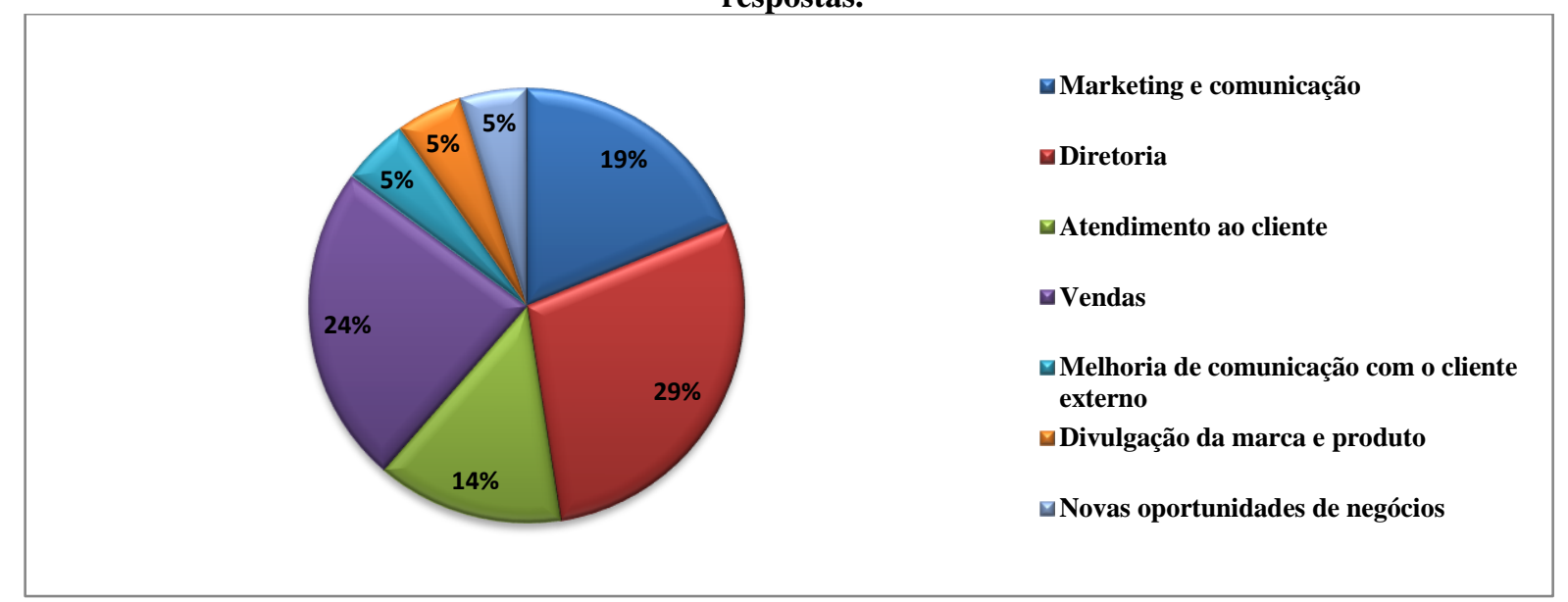

Aos entrevistados foi perguntado: quais as decisões tomadas pelos gestores em função do feedback fornecido pelas Redes Sociais? Pode-se notar que as respostas variam de opiniões (figura 02). Percebe-se que a maioria dos entrevistados decidiu investir mais em marketing após o feedback dos clientes pelas redes sociais. 
Figura 02. Decisões tomadas em função do feedback, Tangará da Serra, 2012, em percentual de respostas.

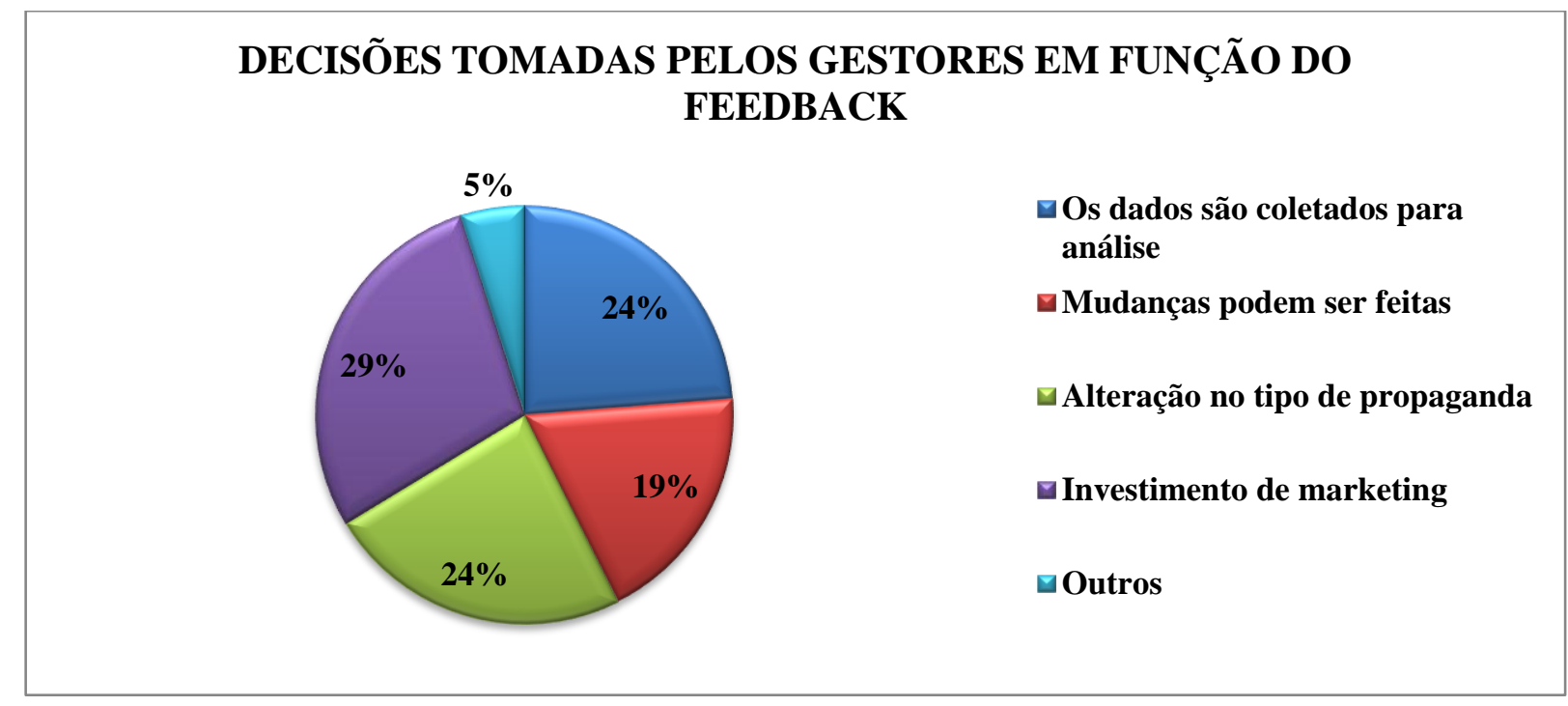

Constatou-se que, na opinião de $100 \%$ dos entrevistados, é relevante o uso das redes sociais como ferramenta de marketing. Foi respondida pelos entrevistados uma questão aberta. Esta serviu para que os entrevistados pudessem deixar sua opinião sobre esse canal que é o Facebook (quadro 2). Percebe-se, pela leitura do quadro 2, que a avaliação do uso dessa rede foi positivo para os entrevistados.

Quadro 02 - Transcrição da opinião dos entrevistados sobre o Facebook, Tangará da Serra, 2012, em número de respostas.

\begin{tabular}{|c|c|}
\hline EMPRESA 1 & $\begin{array}{c}\text { "Ferramenta que nos retorna os melhores feedback } \\
\text { tanto para atender solicitação de clientes como para } \\
\text { venda propriamente de produtos." }\end{array}$ \\
\hline EMPRESA 2 & $\begin{array}{l}\text { "Nossas vendas aumentaram, conhecemos novos } \\
\text { clientes através do Face...Não temos custos com } \\
\text { propaganda. Até o custo do telefone diminuiu na loja, } \\
\text { pois fechamos as vendas através do Face. Ótima } \\
\text { ferramenta para o comércio". }\end{array}$ \\
\hline EMPRESA 3 & $\begin{array}{l}\text { "Ferramenta gratuita, posts em tempo real, retorno } \\
\text { rápido, suporta fotos e vídeos, links externos e bate } \\
\text { papo instantâneo. Só falta o sistema pagseguro para } \\
\text { melhorar de vez". }\end{array}$ \\
\hline EMPRESA 4 & $\begin{array}{l}\text { "Ferramenta muito útil para divulgação da marca e dos } \\
\text { produtos da empresa, além de permitir manter os } \\
\text { clientes sempre informados com novidades e notícias". }\end{array}$ \\
\hline EMPRESA 5 & $\begin{array}{c}\text { "O Facebook está na moda, neste caso as pessoas se } \\
\text { dedicam mais a ele e se sentem mais antenadas, } \\
\text { gostam do status, e com isso aproveitamos para manter } \\
\text { um contato mais direto e um marketing muito mais } \\
\text { barato." }\end{array}$ \\
\hline
\end{tabular}




\subsection{Observação das empresas no Facebook}

Através da observação pode-se constatar que das empresas que indicam o endereço da empresa 42,52\% não detalham dados sobre a empresa, 18,90\% detalham os dados, já as empresas que indicam o endereço houve uma diferença de $1,52 \%$ sendo maior para os que detalham dados sobre a empresa, e desse total de empresas 2,36\% estão desativadas, não utilizando mais o Facebook (tabela 06).

Tabela 06. Divulgação do Endereço e dados sobre a empresa.

\begin{tabular}{c|c|c|c|c}
\hline \multirow{2}{*}{ Indica o endereço? } & \multicolumn{2}{|c|}{ Tem dados detalhados no perfil? } & \multirow{2}{*}{ Total Geral } \\
\cline { 2 - 4 } & Não & Sim & Desativado & \\
\hline Não & $42,52 \%$ & $18,90 \%$ & $0,00 \%$ & $61,42 \%$ \\
\hline Sim & $17,32 \%$ & $18,90 \%$ & $0,00 \%$ & $36,22 \%$ \\
\hline Desativado & $0,00 \%$ & $0,00 \%$ & $2,36 \%$ & $2,36 \%$ \\
\hline Total Geral & $\mathbf{5 9 , 8 4 \%}$ & $\mathbf{3 7 , 8 0 \%}$ & $\mathbf{2 , 3 6 \%}$ & $\mathbf{1 0 0 , 0 0 \%}$ \\
\hline
\end{tabular}

O cruzamento de dados das postagens realizadas por cada empresa mostra que as empresas que menos fazem postagens em sua maioria são postagens pessoais ao contrário das que mais tem postagens só de uso comercial. Considerou-se postagem comercial aquela que tivesse algum meio de divulgação da marca ou de produtos. As postagens pessoais incluíram fotos, mensagens, reportagens, entre outros não realizados com finalidade de marketing da empresa. Sendo assim, pode-se perceber que o uso do Facebook em Tangará da Serra ainda como ferramenta de trabalho ainda é pequeno, pois não há uma distribuição de postagens uniformes entre comerciais e pessoais (tabela 07).

Tabela 07. Quantidade de Postagens.

\begin{tabular}{ccc}
\hline Postagens/Mês & Postagens comerciais & Postagens pessoais \\
\hline 0 a 10 postagens & $62,99 \%$ & $85,83 \%$ \\
11 a 20 postagens & $10,24 \%$ & $0,79 \%$ \\
21 a 30 postagens & $7,87 \%$ & $4,72 \%$ \\
31 a 41 postagens & $5,51 \%$ & $1,57 \%$ \\
41 a 50 postagens & $3,15 \%$ & $1,57 \%$ \\
51 a 60 postagens & $1,57 \%$ & $0,79 \%$ \\
61 a 70 postagens & $2,36 \%$ & $0,79 \%$ \\
70 ou mais postagens & $3,15 \%$ & $0,79 \%$ \\
Perfil desativado & $3,15 \%$ & $3,15 \%$ \\
\hline Total Geral & $\mathbf{1 0 0 , 0 0 \%}$ & $\mathbf{1 0 0 , 0 0 \%}$ \\
\hline
\end{tabular}


Quantificou-se o número de contatos das 127 empresas analisadas. O objetivo foi verificar se as postagens delas poderiam atingir maior número de clientes em potencial. Quanto mais contatos, mais clientes em potencial a empresa teria. A quantidade de contatos das empresas varia. A faixa de 301 à 600 e a de 3001 ou mais contatos são as que mais se destacam com $14,17 \%$ cada uma, conforme tabela 8 . Isso mostra que na faixa de mais de 3001 contatos, as empresas poderiam atingir melhor seus objetivos de divulgação da marca e dos produtos, melhorando suas receitas de vendas. Na contramão, as empresas tem postado pouco e, principalmente, postagens pessoais ao invés de comerciais.

Tabela 08.Quantidade de contatos.

\begin{tabular}{cc}
\hline Número de contatos & \% \\
\hline 0001 à 300 contatos & $5,51 \%$ \\
0301 à 600 contatos & $14,17 \%$ \\
0601 à 900 contatos & $13,39 \%$ \\
0901 à 1200 contatos & $9,45 \%$ \\
1201 à 1500 contatos & $10,24 \%$ \\
1501 à 1800 contatos & $8,66 \%$ \\
1801 à 2100 contatos & $7,87 \%$ \\
2101 à 2400 contatos & $7,09 \%$ \\
2401 à 2700 contatos & $3,94 \%$ \\
2701 à 3000 contatos & $3,15 \%$ \\
3001 ou mais contatos & $14,17 \%$ \\
Desativado & $1,57 \%$ \\
Não informou & $0,79 \%$ \\
\hline Total Geral & $\mathbf{1 0 0 , 0 0 \%}$ \\
\hline
\end{tabular}

Das 127 empresas que foram pesquisadas $11,81 \%$ são do ramo de confecções e 6,30\% do ramo alimentício e 51,18\% outros. Pode-se constatar que são vários os ramos que utilizam o Facebook (tabela 9).

Tabela 09. Ramo de Atividade

\begin{tabular}{ccc}
\hline $\mathbf{N}$ & Ramo de atividade & \% \\
\hline 1 & Confecções & $11,81 \%$ \\
2 & Alimentício & $6,30 \%$ \\
3 & Educação & $4,72 \%$ \\
4 & Musical & $3,94 \%$ \\
5 & Fotografia & $3,15 \%$ \\
6 & Fabricação de móveis & $2,36 \%$ \\
\hline
\end{tabular}




\begin{tabular}{|c|c|c|c|c|c|c|c|}
\hline 7 & \multicolumn{4}{|c|}{ Calçados } & & \multicolumn{2}{|c|}{$2,36 \%$} \\
\hline 8 & \multicolumn{4}{|c|}{ Floricultura } & & \multicolumn{2}{|c|}{$2,36 \%$} \\
\hline 9 & \multicolumn{4}{|c|}{ Comunidade } & & \multicolumn{2}{|c|}{$2,36 \%$} \\
\hline 10 & \multicolumn{4}{|c|}{ Informática } & & \multicolumn{2}{|c|}{$2,36 \%$} \\
\hline 11 & \multicolumn{4}{|c|}{ Bicicletaria } & & \multicolumn{2}{|c|}{$2,36 \%$} \\
\hline 12 & \multicolumn{4}{|c|}{ Vidraçaria } & & \multicolumn{2}{|c|}{$2,36 \%$} \\
\hline 13 & \multicolumn{4}{|c|}{ Estética } & & \multicolumn{2}{|c|}{$2,36 \%$} \\
\hline 14 & \multicolumn{4}{|c|}{ Outros } & & \multicolumn{2}{|c|}{$51,18 \%$} \\
\hline & \multicolumn{4}{|c|}{ Total } & & \multicolumn{2}{|c|}{$100,00 \%$} \\
\hline \multicolumn{8}{|c|}{ Tabela 10. Setor de Atividade versus Média de Postagens, contatos, fotos e mapas. } \\
\hline Valores & Autonomo & Comércio & Comunidade & Outros & Serviço & Terceiro Setor & Total Geral \\
\hline $\begin{array}{l}\text { Média de Post } \\
\text { comercial }\end{array}$ & 5 & 15 & - & 3 & 21 & 21 & 17 \\
\hline $\begin{array}{l}\text { Média de Post } \\
\text { pessoal }\end{array}$ & 12 & 5 & - & 2 & 7 & 0 & 5 \\
\hline $\begin{array}{l}\text { Média de Quantidade } \\
\text { de contatos }\end{array}$ & 806 & 1.366 & 1.230 & 2.373 & 2.325 & 2.481 & 1.750 \\
\hline $\begin{array}{l}\text { Média de Quantidade } \\
\text { de fotos }\end{array}$ & 10 & 84 & 32 & 3 & 86 & 13 & 80 \\
\hline $\begin{array}{c}\text { Média de Quantidade } \\
\text { de Mapas }\end{array}$ & 4 & 12 & 7 & 18 & 12 & 116 & 15 \\
\hline
\end{tabular}

$\mathrm{Na}$ tabela 10 podemos constatar que se considerarmos a quantidade de postagens comerciais versus postagens pessoais, o ramo de comércio, serviço e o terceiro setor procuram não postar mensagens pessoais, já o ramo autônomo tem mais postagens pessoais do que comerciais, pois conciliam o trabalho com a vida pessoal, por se tratar de uma ferramenta gratuita poderiam optar por criar duas páginas: uma para venda e divulgação do produto ou serviço e outra pessoal. Na tabela 10 também verificamos que a média de fotos postadas se sobressai o comércio e serviço, porém não foi verificado se essas fotos são pessoais ou comerciais.

\section{CONSIDERAÇÕES FINAIS}

Conforme os dados coletados podem considerar, que em Tangará da Serra o meio de comunicação pelas redes sociais dentre as empresas é novo, pois foram enviado link com o questionário para 127 empresas e apenas 21 responderam um percentual baixo de 16,53\%, esse percentual nos aponta que por se tratar de uma ferramenta de fácil acesso o uso do Facebook pelas empresas em Tangará da Serra-MT ainda está engatinhando, pois as mesmas em sua maioria não conseguem dar manutenção e retorno aos seus clientes.Estão aprendendo a utilizar essa ferramenta que adentrou o mercado e já conquistou os consumidores. Dentre as empresas que responderam o questionário, ficou comprovado,que é unânime a opinião de que 
o uso do Facebook é relevante e que pode sim ser utilizado para a conquista de novos clientes

e fidelizar os já existentes, como também realizar vendas e trazer melhorias com os feedback fornecidos pelos clientes, diminuindo custo em comunicação e marketing. A preocupação do resultado acima, é que os gestores das empresas de Tangará da Serra devem ter o cuidado ao criar páginas sociais das empresas e abandoná-las, pois isso pode ser revertido em um Marketing Negativo para a empresa. Acredito que daqui alguns anos esse quadro terá uma grande alteração, conforme o passar dos tempos cada vez mais há uma preocupação em fidelização de clientes, por tanto as empresas terão que ficar atentas com suas propagandas de marketing.

\section{REFERÊNCIAS}

BEUREN, Ilse Maria. Como elaborar trabalhos monográficos em contabilidade: teoria e prática. 2 editora São Paulo, Atlas, 2004.

CASTELLS, Manuel A Sociedade em rede, São Paulo Editora Paz e Terra S/A-2003

CAVALCANTI, Elmano Pontes. Revolução da Informação: Algumas Reflexões (1995). Disponível em: <http://www.ancibe.com.br/artigos\%20de\%20si/artigo\%20$\% 20$ Revolu\%C3\%A7\%C3\%A3o\%20da\%20informa\%C3\%A7\%C3\%A3o\%20$\% 20$ algumas\%20reflex\%C3\%B5es.pdf> Acessado em 15/04/12 as 11:10.

CEMBRANEL, PRISCILA;SMANEOTO, CECILIA A influência das redes sociais virtuais nas empresas públicas e privadas (2010). Disponível em: <http://www.retornors.com.br/influencia-das-redes-sociais-virtuais-nas-empresas-publicas-e-privadas $>$ acessado 06/04/12 as 15:00. <http://pt.wikipedia.org/wiki/Rede_social disponível em 15/04/12 as $14: 49>$

CETIC <http://www.cetic.br/pesquisas-cetic.htm disponível 24/03/2012 as 14:28>

COSTA, Liliana Alves (2001). O Sistema de marketing de rede:uma estratégia de acao mercadológica. Disponível em:

<http://www.lume.ufrgs.br/bitstream/handle/10183/3027/000285605.pdf?sequence=1 >

Acessado em:14/04/2012 as 22:03

DI AGUSTINI; VILHA, Carlos Alberto; Ana Patricia Morales, Marketing para bens de consumo durável, Editora FGV 01/01/2002.

DUBNER, Alan. Mídia Social. Disponível em: 〈http://www.midiasocial.com.br/home/>. Acessado em: 15/04/12 as 15:32

FELIPINI DAILTON, ABC do e-comerce distribuição gratuita <www.abcecomerce.com.br> disponível em 01/05/2012 as 11:10. 


\section{IBGE, Censo}

demográfico2010<http://www.ibge.gov.br/home/estatistica/populacao/censo2010/default.sht m> disponível 24/3/12 as 13:40.

KOTLER PHILIP, (1999). Marketing para o século XXI, Editora Caramelo.

LAS CASAS, Alexandre Luzzi Novos rumos do marketing, São Paulo Editora Atlas S.A2001.

LAZZAROTTO, Maiara; MELZ, Laércio Juarez. Redes sociais no curso de Ciências Contábeis da Unemat- Campus Tangará da Serra. Revista UNEMAT de Contabilidade. v.1. n.1. jan-jun, 2012.

MAGALHÃES, Evaldo Fonseca, Os Jornalistas do "Estado de Minas" e o uso da Internet Como Fonte de Pesquisa no Trabalho (2005). Disponível em: $<$ ttp://www.bibliotecadigital.ufmg.br/dspace/bitstream/1843/VALA6KFP42/1/mestrado__evaldo_fonseca_magalhaes.pdf > Acessado em 15/04/12 as 11:28.

MARTINS, C. G.; FERREIRA, M. L. R. O survey como tipo de pesquisa aplicado na descrição do conhecimento do processo de gerenciamento de riscos em projetos no segmento da construção. VII Congresso Nacional de Excelência em Gestão, 12 e 13 ago 2011. Disponivel em: <http://www.excelenciaemgestao.org/Portals/2/documents/cneg7/anais/T11_0362_1839.pdf>. Acesso em: 11 ago 2012.

MENDES, Alexandre. Artigo Redes sociais, sucesso em 2012? (2012) Disponível em <http://imasters.com.br/artigo/23738/redes-sociais/redes-sociais-sucesso-em-2012> Acessado em 29/04/2012 11:00.

NEVES, JOSÉ LUIS (1996), Pesquisa Qualitativa- características, uso e possibilidades. Disponível em: <http://www.ead.fea.usp.br/Cad-pesq/arquivos/C03-art06.pdf disponível em> Acessado em: 01/05/2012 as 13:30.

CLIENTE S.A: cliente opina mais na internet 29/11/2011 Disponível em:

$<\mathrm{http}$ ://www.clientesa.com.br/especial/44412/cliente-opina-mais-na-inte.aspx > Acessado em: 14/04/12 as 17:20.

REVISTA VEJA <http://veja.abril.com.br/blog/vida-em-rede/orkut/novo-recurso-do-orkut-euma-velha-estrategia-do-facebook/\#more-25811 disponível 18/03/12 as 10:07>

RICHARDSON, R. J. Pesquisa Social: métodos e técnicas. São Paulo: Atlas, 1999.

SBARAI, Rafael. Orkut faz 8 anos sem razão para comemora. Revista Veja. Disponível em: < http://veja.abril.com.br/blog/vida-em-rede/orkut/orkut-faz-8-anos-sem-razao-paracomemorar/> Acessado em 03/05/2012 as 00:32.

SORDI, José Osvaldo de, Gestão por processos (2008). Editora Saraiva, São Paulo.

SURVEY disponível em < http://pt.wikipedia.org/wiki/Marketing_digital> acessado em: 01/05/2012 as 12:09. 
TARDIN, Michelle Thomazini, As interferencias da linguagem utilizadas nas "salas de bate papo" na modalidade escrita formal. monografia apresentada para conclusão do curso de Letras do Campus de Tangará da Serra 2010.

TELLES, Andre. Definição de rede social e mídia social. 2010. Disponível em:

<http://www.midiatismo.com.br/comunicacao-digital/definicao-de-rede-social-e-midiasocial>. Acessodo em 15/04/12 as 15:17.

TORRES, Adriano $3^{\text {a }}$ Premio de mídia estadão Edição 2000.

TUBINO LAGUE, DANIELLE. O Marketing digital e as oportunidades das redes sociais para as marcas.

VALE ALBERTO (2012) Artigo marketing nas redes sociais.

$<$ http://ecommercenews.com.br/artigos/cases/marketing-nas-redes-sociais>.

VAZ, CONRRADO ADOLPHO Os 8Ps do marketing digital, (2011). Disponível em: $<$ http://www.clickmarketing.com.br/arquivos-pdf/livros/capitulo1-livro-8ps-do-marketingdigital-conrado.pdf> Acessado em 24/03/2012 as 19:09.

VIEIRA, Marli Vick (2008), Confiabilidade no uso da wikipédia como fonte de pesquisa escolar. Disponível em: http://tecnologiasnaeducacao.pro.br/revista/a1n1/art4.pdf Acessado em: 15/09/2012 às 11:19.

XAVIER, CARLOS ANTONIO (2011), Como fazer e apresentar trabalhos científicos em eventos acadêmicos. Editora Respel Ltda.

ZEVALLOS JUNIOR, Ruben. A história da internet, 2009. Disponível em:

<http://www.artigonal.com/ti-artigos/a-historia-da-internet-737117.html>. Acessodo em: 15 abril 2012. As 14:13. 